\title{
Social interaction between drugged and undrugged rats
}

\author{
SANDRA E. FILE and J. H. POPE \\ City of London Polytechnic Institute \\ Central House, Whitechapel High Street, London E1 7PF England
}

\begin{abstract}
Social interaction between two rats placed in a hole-board apparatus was studied. The duration and frequency of active contact was higher for animals housed singly than for those housed in pairs, and for those tested with an unfamiliar rather than a familiar partner. Animals housed alone had a higher frequency and duration of passive contact, but the familiarity of the partner did not affect this measure. Chlorpromazine reduced the frequency of active contact but increased the frequency and duration of passive contact. When only one of the pair was drugged, both rats showed more frequent changes from one behavior to another, compared with pairs where both were in the same drug state. Animals housed alone showed the highest number of changes in behavior, and those tested with an unfamiliar partner showed a higher level than those tested with a familiar one.
\end{abstract}

The purpose of this experiment was to study the social behavior of rats in a test situation that permitted physical contact between the animals. Under such conditions (e.g., Silverman, 1965; Latané, 1969), more social behavior is observed than when the animals are separated by a barrier (e.g., Antonitis \& Kish, 1955; Lindzey, Winston, \& Roberts, 1965). The hole-board apparatus was selected as the test situation, since it was an environment novel to both animals and, unlike the home cage, would not be biased toward eliciting aggressive and escape responses (Chance \& Silverman, 1964).

Rats interact less with an anesthetized than with an undrugged animal (Latané \& Glass, 1968; Becker et al, 1973), and in this experiment the effect on social behavior of a milder drug state was investigated. Chlorpromazine was chosen because it had been found that small doses of this drug did not reduce the total time the rats spent in contact with each other (File \& Pope, 1974) and, therefore, would provide an opportunity for measuring any qualitative changes in social behavior as a result of one or both of the animals being drugged.

The housing conditions and familiarity of the partner are likely to affect social interaction (Latané, Cappell, \& Joy, 1970; Latané, Schneider, Waring, \& Zweigenhaft, 1971); therefore, these factors were also varied in this experiment. Since chlorpromazine reduces aggressive behavior (Silverman, 1965) and it is this behavior which leads to the establishment of a rank order in male rats (Chance \& Silverman, 1964), it was possible that the effect of chlorpromazine on social behavior would be dependent on the social rank of the rat. Therefore, when the rats were housed in pairs and tested with their cagemates (and had thus had the opportunity of developing a dominant/subordinate rank), the factor of social rank was systematically varied in every drug condition.

\section{METHOD}

\section{Subjects}

One hundred and forty-four male hooded rats, $250-300 \mathrm{~g}$, were housed in 12 -h light $/ 12-\mathrm{h}$ dark cycle (lights on from $800 \mathrm{~h}$ ) at a constant temperature of $21^{\circ} \mathrm{C}$, with food and water available ad lib. The 40 rats in Housing Condition $A$ were housed alone, and the remaining rats were housed in pairs. The initial weight difference between the members of any pair was no more than $5 \mathrm{~g}$. All animals were kept in these housing conditions for 3 weeks prior to the start of the experiment.

\section{Apparatus}

The apparatus was a wooden box with a floor $66 \times 56 \mathrm{~cm}$ in which there were 16 round holes, $3.8 \mathrm{~cm}$ in diam, $10 \mathrm{~cm}$ apart. Each hole was $1 \mathrm{~cm}$ deep, and the apparatus was placed $2 \mathrm{~cm}$ above the floor of the room. The box had sides $47 \mathrm{~cm}$ high that prevented the animal from escaping and provided a constant visual environment. Testing took place in the room where the rats were housed, under the normal room illumination (80-W strip light $3 \mathrm{~m}$ above the floor), and with normal air conditioning, which masked noises from other rooms. Two observers sat on opposite sides of the box, at a height of $110 \mathrm{~cm}$ and a distance of $84 \mathrm{~cm}$ from the center of the box.

\section{Procedure}

There were three housing conditions in this experiment: Forty rats were housed alone and tested with an unfamiliar partner (Condition A), 40 were housed in pairs but tested with an unfamiliar partner (B), and 64 were housed in pairs and tested with their cagemate $(C)$.

There were also three drug conditions: In the S-S group both rats received saline injections, in the D-D group both received an injection of $2 \mathrm{mg} / \mathrm{kg}$ chlorpromazine, and in the S-D group one rat received saline and the other $2 \mathrm{mg} / \mathrm{kg}$ chlorpromazine. From each of the Housing Conditions $A$ and $B, 10$ rats were randomly assigned to the S-S group, 10 to the D-D group, and 20 to the S-D group (10 having saline injections and 10 the drug).

The 64 rats in Housing Condition $C$ were studied in the home cage on the day before experimental testing in order to determine which of the rats in each cage was the dominant member of the pair. The animals were water deprived for $4 \mathrm{~h}$ and then observed for $5 \mathrm{~min}$ immediately after the water bottle had been replaced. The animal spending longer at the spout and submitting least of ten was classified as the dominant member of the pair. Both animals were then marked with a felt-tipped pen, 


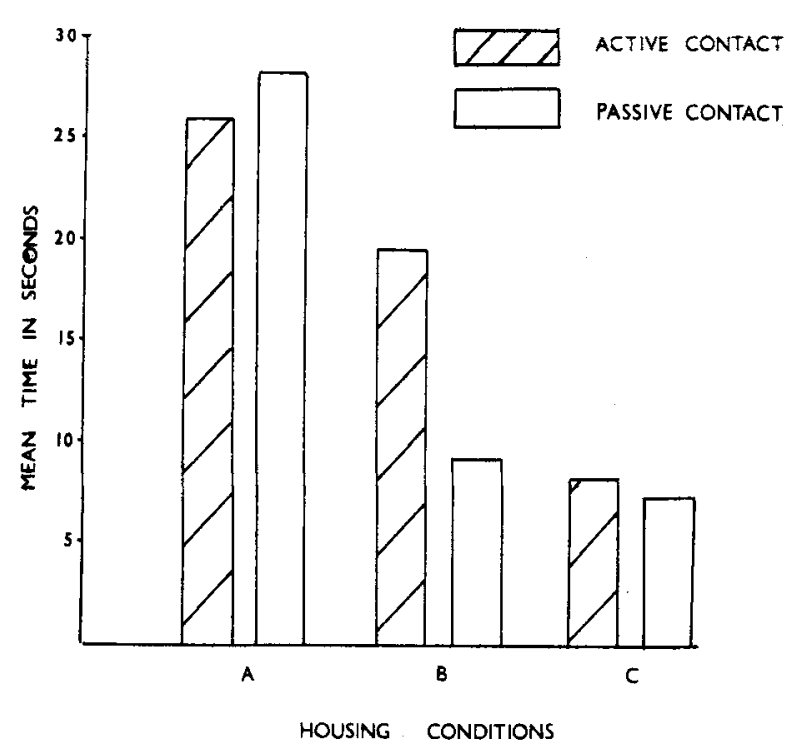

Fig. 1. Effect of housing conditions on the duration of active and passive contact.

replaced in the home cage, and observed for another $3 \mathrm{~min}$. The handling and marking of the animals produced a short period of aggressive behavior, and the number of times each rat showed a submissive posture was recorded. The rat submitting less frequently was considered the dominant member of the pair, and in no case did this classification conflict with the earlier one based on competition for the water spout. However, the second observation period produced more marked distinctions between the members of each pair. Sixteen rats from Condition $C$ were randomly allocated to both Groups D-D and S-S and the behavior of both the dominant and the subordinate animals scored. Thirty-two animals were assigned to Group S-D, and within this group half of the animals tested under saline conditions were those previously designated as dominant and half were subordinate. A similar division of animals was made between those tested drugged.

Since the time of day and level of food deprivation affects exploration in the hole-board apparatus (File \& Day, 1972), only six rats or pairs of rats were tested on any one day in order to minimize variations from the prescribed time of testing. The order of testing within each day and from day to day was randomized between all the groups. On the day of testing, food was removed from two animals or pairs of animals at 1130 , 1200 , and $1230 \mathrm{~h}$ and the animals then tested at 1530,1600, and $1630 \mathrm{~h}$, respectively. All injections were given ip $1 \mathrm{~h}$ before the time of testing.

Each pair of rats was placed in the center of the hole-board and the behavior of.one rat recorded by Observer $A$ and that of the other rat by Observer B. Observer A had no knowledge of which group was being tested on any occasion but, since the injections were done by Observer $B$, these observations could not be "blind." In the S-D group each observer recorded the behavior of the drugged animal in 10 of the pairs and of the saline animal in the other 10 , although Observer $A$ did not know when this group was being tested nor the drug state of the animal observed. The rats were given a single $12-\mathrm{min}$ trial in the apparatus, during which time the following responses were registered on a multichannel event recorder operated by silent switches: sniff, follow, mount, groom the partner, attack, aggressive behavior not classifiable as attack, e.g., nip, passive contact with the partner, and head dips.

\section{RESULTS}

During the 12-min trial, eight separate measures of each rat's behavior had been recorded. For the purposes of analysis, the first six behaviors listed above were combined into a classification of active contact, with passive contact (i.e., a rat being in body contact with the other but without initiating it or trying to escape from it) forming the other category. Both the frequency and duration of the responses were analyzed and, where necessary, a $(\sqrt{x}+\sqrt{x+1})$ transform was used to normalize the data.

Due to occasional apparatus failures, there were not data from all 144 animals on all measures, but the number of scores used is always indicated in the degrees of freedom quoted.

First, for Housing Condition $\mathrm{C}$ a comparison was made of the behavior of dominant and subordinate rats, but there was no difference between the duration of active contact $(\mathrm{F}=0.87, \mathrm{df}=1 / 56, \mathrm{p}>.05)$ nor between the duration of passive contact $(F=0.38$, $\mathrm{df}=1 / 56, p>.05$ ) for either the drugged or the undrugged animals. The data for the dominant and subordinate rats were, therefore, combined for all the following analyses.

Consider, first, the amount of time the rats spent in active contact with the partner. It can be seen from Fig. 1 that rats housed alone had a larger mean duration of active contact than those housed in pairs and that, if the partner was familiar, the time spent in active contact was further reduced (comparing Conditions B and C). This effect of housing conditions on active contact was significant at $\mathrm{p}<.01(\mathrm{~F}=24.2, \mathrm{df}=2 / 130)$. However, there was no significant drug effect on the duration of active contact $(\mathrm{F}=1.97, \mathrm{df}=3 / 130, \mathrm{p}>.05)$, although the D-D group had a mean of only 15.1 , as compared with a mean of 25.0 for the saline rats in Group S-D.

The frequency analysis of active contact also reflected a significant effect of housing conditions $(F=20.1$, $\mathrm{df}=2 / 131, \mathrm{p}<.01$ ), with mean frequencies of 27.6 , 17.6 , and 10.3 for Conditions $\mathrm{A}, \mathrm{B}$, and $\mathrm{C}$, respectively. Chlorpromazine significantly reduced the frequency of active contacts to a mean of 15.9 , compared with a mean of 31.0 for undrugged rats $(F=4.6, d f=3 / 130$, $\mathrm{p}<.05)$.

Second, considering the time spent in passive contact with the partner, there was again a highly significant housing effect $(\mathrm{F}=47.3 \mathrm{df}=2 / 131, \mathrm{p}<.01)$. It can be seen from Fig. 1 that animals housed alone spent more than twice as long in passive contact with their partners than did those housed in pairs, but the familiarity of the partner had little effect. The frequency of passive contact also showed a significant housing effect $(F=57.0, \quad d f=2 / 131, p<.01)$, with frequencies of $17.6,6.5$, and 5.2 for Conditions $\mathrm{A}, \mathrm{B}$, and $\mathrm{C}$, respectively.

The time spent in passive contact also reflected a significant drug treatment effect $(\mathrm{F}=4.1, \mathrm{df}=3 / 131$, $\mathrm{p}<.05$ ), the drugged animals spending significantly longer in passive contact (16.5 for Group D-D, 20.5 for the drugged rats in Group S-D, 12.6 for Group S-S, and 9.6 for the saline animals in Group S-D). However, the 
Fig. 2. Effect of housing conditions and drug treatment on the number of category changes.

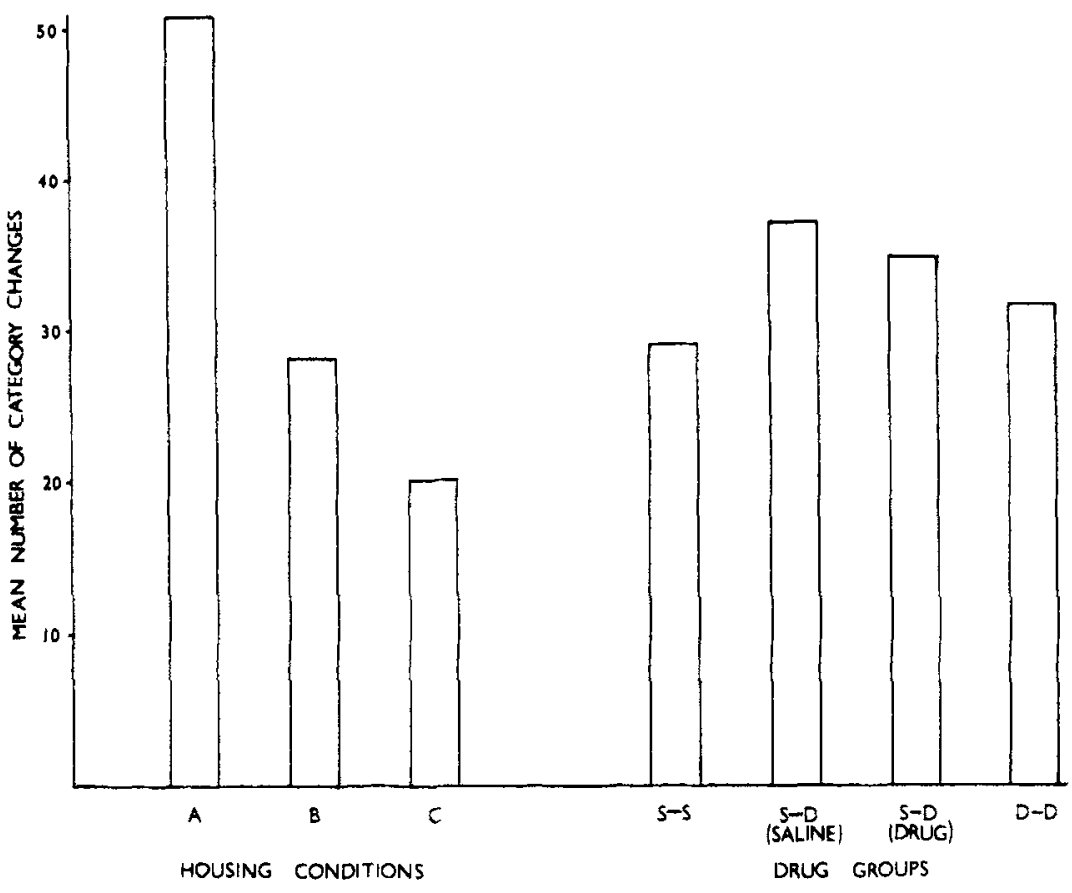

state of the partner did not significantly affect the time spent in passive contact for either the drugged animals (a priori t test between D-D and the drugged rats in S-D, $t=1.3, d f=131, p>.05$, one-tailed test) or for the undrugged animals (a priori t test between S-S and saline rats in $S-D, t=1.2$, df $=131, p>.05$, one-tailed test). The frequency of passive contacts was also increased by chlorpromazine to a mean of 11.4, compared with a mean of 8.1 for the saline injected rats $(F=6.2$, $\mathrm{df}=3 / 131, \mathrm{p}<.05)$.

Because the duration of head dips was always very brief, analysis of this was carried out using the frequency data only. The housing conditions did not affect the number of head dips made, i.e., exploration of the apparatus $(F=1.4, d f=2 / 126, p>.05)$, which contrasts with their effects on measures of social interaction. Chlorpromazine did not reduce the number of head dips made $(F=0.64$, df $=3 / 126, p>.05)$, replicating the results of a previous experiment (File \& Pope, 1974) which found that, in conditions of social testing, chlorpromazine did not reduce the number of head dips.

Finally, an analysis was made of the number of category changes for each rat during the $12-\mathrm{min}$ trial, e.g., if a rat head dipped, then followed the partner, and then sniffed him, this would be counted as two category changes. For this analysis, all eight behaviors recorded were used. A significant housing effect was found $(\mathrm{F}=88.3, \mathrm{df}=2 / 125, \mathrm{p}<.01)$ and a significant drug effect was found $(F=3.1$, df $=3 / 125, p<.05)$, as shown in Fig. 2. In the drug group, the highest number of category changes was shown by rats tested with a partner in a different state than themselves, i.e., Group S-D. This measure could have been affected by the number of different responses the rat made in the situation, e.g., the drugged rats may have shown no aggressive behaviors and, hence, would have had a total of only six different categories of behavior to change between. Some categories of behavior were only rarely observed, in particular attack, which was scored for less than $10 \%$ of the rats, and mount, which was scored for less than $5 \%$. However, the mean number of behavioral categories scored for each group did not vary with the drug treatment $(F=0.6$, df $=3 / 125, p>05)$, so that the fewer category changes of the D-D group were not due to a diminished behavioral repertoire. In contrast, the mean number of categories scored did differ with the housing conditions $(F=9.2, \quad d f=2 / 125, p<.01)$, Condition A showing a mean of 5.5 changes, B 4.2 , and C 4.0. Therefore, to some extent, the greater number of changes in behavior of animals housed alone was a function of a larger behavioral repertoire.

\section{DISCUSSION}

In the hole-board apparatus, the social rank of a rat did not alter the effect of chlorpromazine on the social interaction with its cagemate. But one cannot conclude that the effects of chlorpromazine will be independent of social rank in all situations. The failure to find an effect could have been because the social hierarchy of laboratory rats is not well established (Barnett, 1963) or because the ranking observed in the home cage did not transfer to novel situations.

Alternatively, the results could have been due to the low level of aggression elicited in the hole-board apparatus: Attack was rarely recorded and in only one instance was a full submissive posture observed. A similarly low level of aggression was reported when two rats were placed in an open field (Latané, 1969), and this suggests that, unless one rat is intruding into 
another's territory, their social interaction will not be characterized by aggressive encounters. Chlorpromazine did not reduce the exploration of the apparatus, as measured by the number of head dips made, which replicates the results previously found (File \& Pope, 1974) when two rats were tested together in the hole-board. Neither the condition of housing singly or in pairs nor the familiarity of the test partner affected the exploration of the apparatus. In contrast, all these factors affected the rats' social behavior.

Animals housed alone engaged in both active and passive contact with the partner more frequently and for longer periods than did those housed in pairs. Animals housed alone only showed higher levels of social interaction after 4 days of testing in the open field (e.g., Latané, Cappell, \& Joy, 1970). Latané suggested that the housing conditions only affected social behavior when the test situation had become familiar and, therefore, little time was spent exploring the apparatus. The results from the hole-board demonstrate that these effects can be observed even on the first trial in the apparatus, although this may well depend on the overall level of social interaction. In generăl, the open field seems a less sensitive situation than the hole-board for studying effects on social behavior. Latané et al (1971) reported that the familiarity of the partner did not affect social interaction between two rats in the open field, whereas in the hole-board an unfamiliar partner increased the frequency and duration of active contact, although passive contact was unaffected.

This suggests that, when a rat actively initiates contact with another, it can partly be explained in terms of social exploration that is increased if the partner provides a set of novel stimuli. However, at least one other factor must underlie active and, more particularly, passive contact between rats, since those housed alone have higher levels than those housed in pairs, even when both are tested with an unfamiliar partner. Latane has suggested that rats may have a need for physical contact, which is increased if they are housed in social isolation (Latané, Cappell, \& Joy, 1970).

Joy and Latané (1971) reported that pairs of rats injected with chlorpromazine maintained a greater distance apart from each other in the open field than did saline injected rats. File and Pope (1974) had contrasting results from the hole-board, where chlorpromazine did not reduce the total time spent in body contact with the other rat, although the particular types of social behavior were not recorded. This experiment gave a more detailed picture and, while the drug reduced the frequency of active contact between rats, it also increased both frequency and duration of passive contact. Therefore, chlorpromazine reduced both the initiation of and withdrawal from social interaction. This would be compatible with the suggestion (Silverman, 1966) that chlorpromazine impairs the ability to change from one type of behavior to another. However, the results from the frequency of category changes do not support such an interpretation, since chlorpromazine did not reduce the number of changes in behavior. When rats were tested with a partner in a different drug state than themselves, there was an increase in the frequency of changes in behavior. This indicates that rats are sensitive to their partner's drug state and that this will be reflected in the detailed pattern of social behavior.

\section{REFERENCES}

Antonitis, J., \& Kish, G. Reactions of C57 black male mice to active and inactive social stimuli. Journal of Genetic Psychology, 1955, 86, 115-130.

Barnett, S. The rat: A study of behavior. London: Methuen, 1963.

Becker, L., Wright, D., Kelley, D., Harkins, S., Majcher, L., \& Lammers, B. The effect of sodium pentobarbital on attraction in the albino rat. Animal Learning \& Behavior, 1973, 1, 77-80.

Chance, M., \& Silverman, A. The structure of social behavior and drug action. In $H$. Steinberg, $A$. de Reuck, and J. Knight (Eds.), Animal behavior and drug action. London: Churchill, 1964. Pp. 65-69.

File, S., \& Day, S. Effects of time of day and food deprivation on exploratory activity in the rat. Animal Behavior, 1972, 20 , 758-760.

File, S., \& Pope, J. The action of chlorpromazine on socially facilitated exploration in the rat. Psychopharmacologia, 1974. in press.

Joy, V., \& Latane, B. Autonomic arousal and affiliation in rats. Psychonom ic Science, 1971, 25, 299-300.

Latane, B. Gregariousness and fear in laboratory rats. Journal of Experimental Social Psychology, 1969, 5, 61-69.

Latané, B., Cappell, H., \& Joy, V. Social deprivation, housing density and gregariousness in rats. Journal of Comparative \& Ph ysiological Psychology, 1970, 70, 221-227.

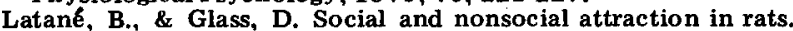
Journal of Personality \& Social Psychology, 1968, 9, 142-146.

Latane, B., Schneider, E., Waring, P., \& Zweigenhaft, R. The specificity of social attraction in rats. Psychonomic Science, $1971,23,28-29$.

Lindzey, G., Winston, H., \& Roberts, L. Sociability, fearfulness and genetic variation in the mouse. Journal of Personality \& Social Psychology, 1965, 1, 642-645.

Silverman, A. Ethological and statistical analysis of drug effects on social behavior of laboratory rats. British Journal of Pharm acology, 1965, 24, 579-590.

Silverman, A. The social behavior of laboratory rats and the action of chlorpromazine and other drugs. Behavior, 1966, 27, 1-37.

(Received for publication November 27, 1973; revision received February 2, 1974.) 